\title{
RESEARCH OF WAYS OF CONNECTING REINFORCED BARS IN THE PRODUCTION OF REINFORCED CONCRETE PRODUCTS
}

\author{
Ayym Yessirkepova \\ Karaganda State Technical \\ University, Faculty of Mechan- \\ ical Engineering, Department \\ of Technological equipment, \\ Mechanical Engineering and \\ Standardization, \\ Karaganda, Kazakhstan
}

\section{Toty Buzauova}

Karaganda State Technical University, Faculty of Mechanical Engineering, Department of Technological equipment, Mechanical Engineering and Standardization, Karaganda, Kazakhstan

\author{
Karibek Sherov \\ Karaganda State Technical \\ University, Faculty of Mechan- \\ ical Engineering, Department \\ of Technological equipment, \\ Mechanical Engineering and \\ Standardization, \\ Karaganda, Kazakhstan
}

\section{Assylkhan Mazdubay}

S. Toraighyrov Pavlodar State University, Faculty of Metallurgy, Mechanical Engineering and Transport, Department of mechanical engineering, Pavlodar, Kazakhstan

\author{
Valentin Mikhailov \\ Karaganda State Technical \\ University, Faculty of Mechan- \\ ical Engineering, Department \\ of Technological equipment, \\ Mechanical Engineering and \\ Standardization, \\ Karaganda, Kazakhstan

\section{Aizhan Taskarina} \\ S. Toraighyrov Pavlodar State \\ University, Faculty of Metal- \\ lurgy, Mechanical Engineering \\ and Transport, Department of \\ mechanical engineering, \\ Pavlodar, Kazakhstan
}

Key words: reinforcement, reinforced concrete, reinforcement waste, resistance welding, lap welding, friction welding

doi:10.5937/jaes18-24319

\section{Cite article:}

Yessirkepova, A., Sherov, K., Mikhailov V., Buzauova T., Mazdubay A., \& Taskarina, A. [2020]. Research of ways of connecting reinforced bars in the production of reinforced concrete products. Journal of Applied Engineering Science, 18(3) 372 - 377. 


\title{
RESEARCH OF WAYS OF CONNECTING REINFORCED BARS IN THE PRODUCTION OF REINFORCED CONCRETE PRODUCTS
}

\author{
Ayym Yessirkepova ${ }^{1}$, Karibek Sherov ${ }^{1 *}$, Valentin Mikhailov' ${ }^{1}$, Toty Buzauova ${ }^{1}$, Assylkhan Mazdubay ${ }^{2}$, \\ Aizhan Taskarina ${ }^{2}$ \\ ${ }^{1}$ Karaganda State Technical University, Faculty of Mechanical Engineering, Department of Technological \\ equipment, Mechanical Engineering and Standardization, Karaganda, Kazakhstan \\ ${ }^{2}$ S. Toraighyrov Pavlodar State University, Faculty of Metallurgy, Mechanical Engineering and Transport, \\ Department of mechanical engineering, Pavlodar, Kazakhstan
}

The authors conduct research on the creation of non-waste technology for the use of reinforcing bars in the manufacture of reinforced concrete products (reinforced concrete). This article presents the results of a study of existing methods for connecting reinforcing bars in the manufacture of reinforced concrete. The connection methods were investigated: mechanical, lap welded. Their advantages and disadvantages are revealed. Welding methods have also been investigated: contact, bathroom docking, contact spot, friction welding. The following main disadvantages inherent in existing methods of connecting reinforcing bars were established: the narrowness of technological capabilities, low quality and accuracy of the connection, the high cost of technological equipment. To address these shortcomings, a new method of friction welding for connecting reinforcing bars is proposed.

Key words: reinforcement, reinforced concrete, reinforcement waste, resistance welding, lap welding, friction welding

\section{INTRODUCTION}

The research of the current condition of the construction industry of the Republic of Kazakhstan (RK) has shown that the domestic building materials industry (in particular reinforcing bars) is currently able to satisfy only part of the needs of the construction complex of the Republic of Kazakhstan, and as a result, imported products make up a significant market share. This current situation negatively affects the prime cost of construction products manufacturing. The results of conducted researches in the conditions of construction enterprises of the Republic of Kazakhstan have shown that there is a large consumption of a rebar for waste, which exceeds the standards defined by State Standard and is about $2 \%$. The consumption of a rebar in this ratio leads to an increase in the prime cost of reinforced concrete products manufacturing, which plays an important role in the current state of the construction industry of the Republic of Kazakhstan.

Reinforcing metal rods (rebars, rods, wires) are an integral part of reinforced concrete products, which, in turn, are actively used in the construction industry.

One of the main purposes of reinforcing elements is to create the greatest rigidity and strength of reinforced concrete products [1].

The modern construction industry involves the high-quality production of reinforced concrete products with the efficient use of building materials while reducing the prime cost of production.

*shkt1965@mail.ru

\section{EXPERIMENTAL AND DISCUSSION OF THE RESULTS}

Various reinforced concrete products can be manufactured, using reinforced metal bars, for example, window or door lintels, staircases and so on.

Reinforcing bars are connected in one of three ways:

- mechanical, lap welding;

- using special joining elements;

- using welding.

Each of the above methods has its advantages, disadvantages and features. The mechanical method of welding involves the use of a hydraulic press and threaded sockets, as well as couplings. The manufacturing technology is the following:

- rods are "dressed" in threaded sockets,

- the hydraulic press enables to compress the coupling around the rod, thereby fixing it securely,

- then the structure is assembled by means of couplings. They can also be replaced with pipes with thick walls.

The advantage of mechanical assembly of a rebar is the speed of work. Some rebar classes require a different joining method, such as lap welding. It is worth noting that when working with reinforcing bars by lap welding, a noticeable percentage of this material is lost. There is also a significant advantage in this method of work, i.e., fasteners are needed, and additional tools, devices are not required.

The rebar joining by lap welding is most often used when 
it is necessary to distribute compressive and tensile loads over entire surface.

There are several rules that must strictly followed when using this method:

- $\quad$ joining by lap welding can only be used on areas with the lowest voltage;

- $\quad$ joining rods must be the same diameter. Only a slight deviation is permitted in exceptional cases;

- $\quad$ this method is permitted to be used only for joining rods, the diameter of which does not exceed $20 \mathrm{~mm}$.

Figure 1 shows arebar joining by lap welding [2].

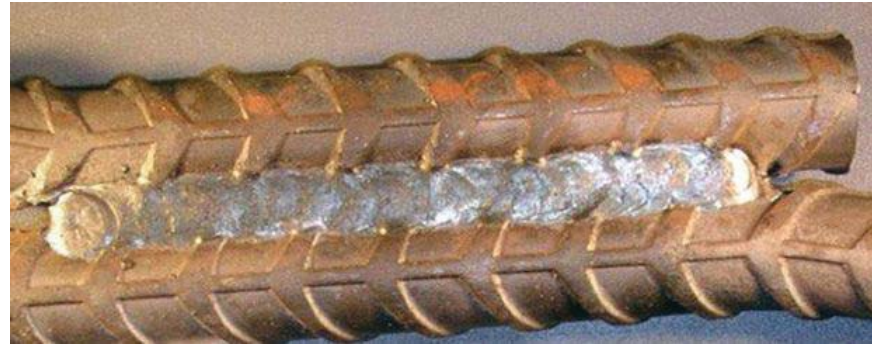

Figure 1: Rebar joining by lap welding

When joining a rebar by lap welding, welds are formed at the contact point of both parts, which provides equilateral support for a finished product. Most often, such joint is used to create metal frames for the future monolith.

Sometimes the rebar joining by overlapping is used without welding. In this case, steel bars at the intersection are connected using wire. This is possible when creating metal structures that will not be subjected to heavy loads. This method is not used in industrial production, but is sometimes used for private construction. Whether tying or welding a rebar depends on for what loads the reinforced structure is mounted.
The third type of joining rebar elements is by welding. The method is quite common and requires complete professionalism.

There are many advantages that enable to make a choice in favor of welding joining, as the most effective, reliable way to join reinforcing bars.

Multilayer welds speak for themselves. First, a weld is applied on one side of a preparation, then,mirroring, isapplied on the other side. Spot joining is needed if a structure with cross passages is used in a reinforced concrete product. Not all grades of steel bars are suitable for spot welding. This is because positions of joint can quickly collapse due to the rapid spot hardening of metal, which makes it very brittle. Advantages of welding compared to other connecting methods:

- welds are quite strong;

- the impact strength of a product becomes much higher;

- $\quad$ the product made by welding is less susceptible to deformation, which means that the original shape of a product is better preserved;

- $\quad$ reinforcing cages or grids practically do not react to external environmental impacts: sun rays, frosts and so on.

Reinforced concrete products are under load associated with constant compression, as well as tension, as they perform a bearing function. Welds made in accordance with State Standard 1409891 make a product more rigid and, at the same time, structure becomes more "elastic", stable and durable [3].

Figure 2 shows varieties ofreinforcing bars joining.

Figure 3 shows a cross-shaped rods joining of a metal frame [2].
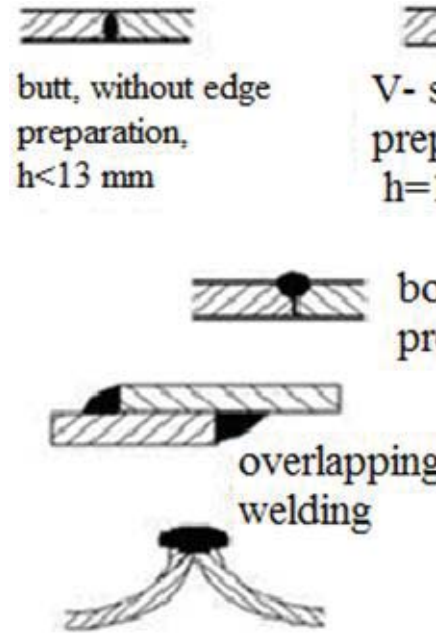

flanged welding

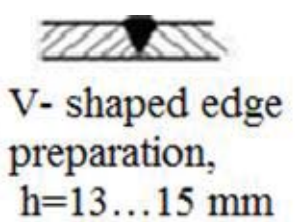

bowl-shaped edge preparation, $\mathrm{h}>20 \mathrm{~mm}$

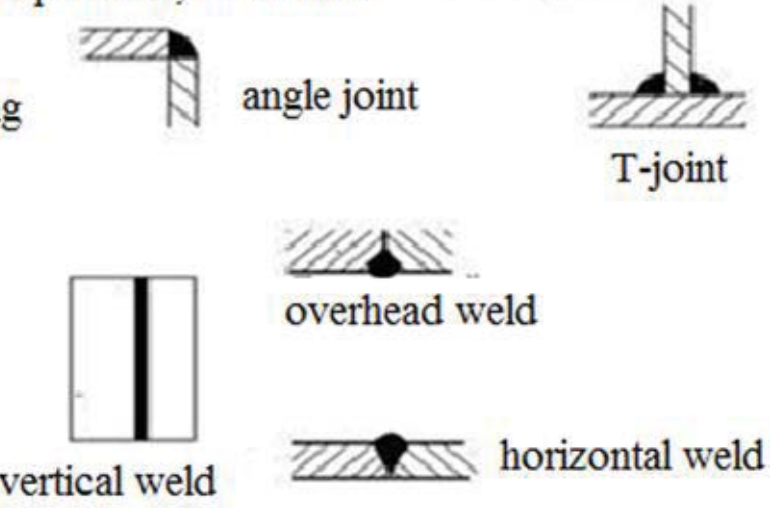

Figure 2: Varieties ofreinforcing bars joining 


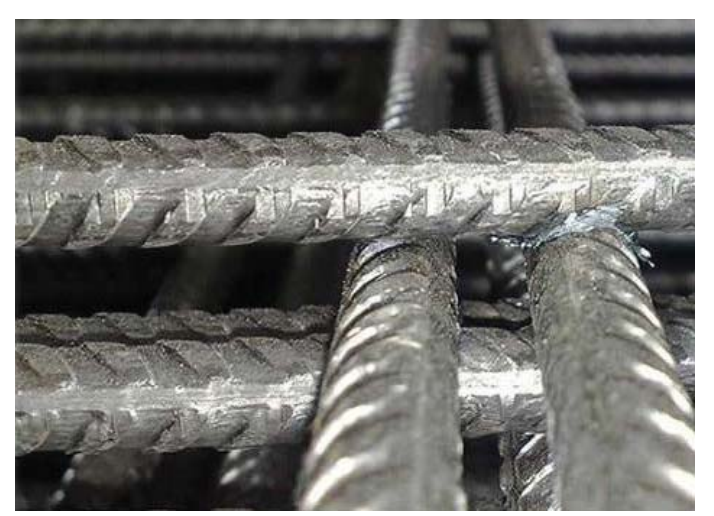

Figure 3: Cruciform joint of a metal frame's bars

Contact welding method is one of the most common welding methods. The contact point of products is melted by heating to a temperature of deformation and compression. This is made by passing current through a circuit, the links of which are rods themselves. The current appears in a closed circuit, and the greatest resistance is concentrated on the contact area of rods. At the same time, heat is generated, which ensures maximum heating of this area.

The welding time can be reduced by increasing the current strength to 10 , and in some cases up to 20 thous and amperes.

In this case, melting of metal occurs almost instantly. Accordingly, the passage of current through the circuit is significantly reduced. Contact joining of products can be carried out by butt or spot method. The first one is used when end parts are butt. Spot welding of a rebar is applied when rods overlap each other. They are joined at several points simultaneously.

A professional device is used to join rods by the contact method. Rebar welding must be carried out at a certain current strength and level of compression of the contact area, at a given time. All equipment is conditionally divided into mobile and stationary. The simplest device can be assembled on one's own. It must include 2 functional nodes. The first is the power supply, the second is contact carriersof the remote type.

The spot joining is used mainly when making reinforcing cages, reinforcing nets from bars with a small cross section.

It is recommended to weld the crosswisejoints of rods of a metal frame by the method of contact spot welding. Using this method enables to producewelded nets, as well as flat frames from a rebar, with their subsequent assembly into spatial structures.

Crosswise spot welding of a rebar is carried out using:

- in single cases or small-scale production - single-point machines of stationary or suspension type;

- for mass industrial production - specialized contact multipoint machines.

For crosswise connections, the tying method can also be used. It enables to connect rods of a rebar of any diameter, mainly up to $20 \mathrm{~mm}$. Rods with a diameter of over $20 \mathrm{~mm}$ are recommended to be welded together, at the same time they makea large contact area during welding.

However, the implementation of spot welding requires the use of powerful expensive equipment, which is inappropriate for construction enterprises of the Republic of Kazakhstan.

Butt welding of a rebar is carried out by connecting the ends of rods over the entire contact area by heating.

Joints can be connected in two ways:

- melting the contacting planes - butts are heated to a state of melting;

- heating the connected parts by the resistance method - when heated, abutt is brought to a plastic state.

Figure 4 shows butt welding of a rebar [2].

Choosing this or that method depends on the grade of used metal, the diameter of a rebar, and also on the requirements for the strength of a joint [4].

There is tub welding. Joining by the tub method is used if the cross section of reinforcing rods is large enough and reaches up to $10 \mathrm{~cm}$. Using the tub joining, flanges are attached to metal pipes, multi-row reinforced hollow "pillars" of any structures are joined, and other reinforcing cages are made [3].

This method is usually used to join:

- reinforcing products ofa large diameter $(2-10 \mathrm{~cm})$;

- butts of bars located in several rows in reinforced concrete structures;

- butts of flanges made of steel strips with a large cross section.

This method of rebar welding is designed forfoundation and other large reinforced concrete products, complex frames when constructing different buildings. It ensures the preservation of the strength of parameters and structural rigidity along the entire length. Such welding ofa rebarenables to create a single bearing frame. The joining can be made both horizontally and vertically. Tub welding of arebar of columns and other vertical products can, therefore, be carried out without moving them and bringing them into a horizontal position. Another advantage is that standard devices are used to make the joining, as in electric arc welding.

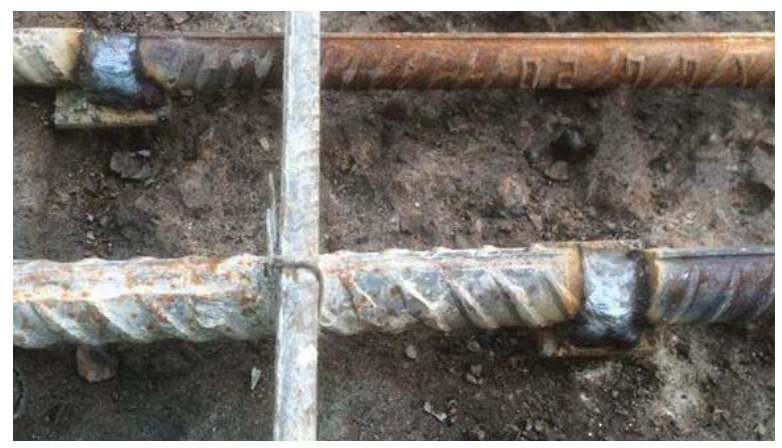

Figure 4: Rebarbutt welding 
A key condition for obtaining high-quality buttsduringtub welding of a rebar is a clear joining of bars. It is necessary to ensure that the axis of rods do not move more than half their section relative to each other. To comply with this condition, conductors of various types are used. In them, the geometric parameters and the location of rods during a rebar welding remain unchanged [5].

In practice, three methods are used: Semi-automatic (in ceramic form). Single, three-phase electric arc using a steel bracket (manual version). Automatic tub-slaggy (in copper form). The most efficient option is when brackets are not used when connecting rods. The fact is that for their manufacture it is necessary to spend a certain time and metal. When there are nobrackets, a compact connection is made.

The disadvantage is that tub welding is performed at currents with high rates. It can be 450 amperes if $5-6 \mathrm{~mm}$ electrodes are used. If products' connection is made at low temperatures, a current of approximately $10 \%$ higher than the standard is used.

When using three-phase welding, a gap of $1.5-2 \mathrm{~cm}$ larger than the diameter of an electrode should be left. The mismatch of axes of reinforcing rods should not exceed $5 \%$ of the cross-sectional area of electrodes. Experts recommend to give the "back deflection" to bars, if they are long.

Quite often, the ends of rods when implementing tub welding connection are slagged. This is due to rapid heat dissipation. As a result, the reliability of the connection is significantly reduced.

One of the productive methods for connecting reinforcing bars is friction welding. Friction welding is used in increasing reinforcing bars, at the same time limiting the number of two joints per 9 meters of the length of a bar is excessive. The number of joints can be brought up to one per meter of length without damaging the strength properties of a rod, which will enable to avoid waste, sometimes reaching $35 \%$ when manufacturing products from a rebar.

Figure 5 shows the friction welding process.

The results of testing the friction welding method conducted in the work [6] showed that the strength of a weld exceeds the strength of the main metal, and the rupture of rods occurred at a considerable distance from a weld and the heat affected zone. It was also found that the cross section of a butt after cutting the flash becomes larger than the effective cross section of a rebar, at the same time the metal in the cross section has a finegrained, equiaxial structure with increased viscosity and strength.

The technological scheme of friction welding is much simpler than electric arc or gas welding. Features of friction welding include:

- the capacity to weld dissimilar materials, for example, to weld steel aluminum. At the same time, filler materials and complex equipment are not required;

- applicability for permanent connection of parts from copper, lead, titanium without deformation ofblanks;

- maximum efficiency is achieved when working with blanks from 6 to 100 millimeters in diameter;

- indispensability in the creation of complex technologies and the production of forged-welded, stamped-welded and welded-molded products;

- the capacity to join materials with low weldability. This method can be used to weld blanks that are not welded by any other methods, for example, aluminum and steel.

Important advantages of friction welding technology include:

Performance. The entire welding process takes from a few seconds to several minutes. Significantly less time takes preparatory and final operations. In this parameter, the technology is better than contact electric welding.

Energy efficiency. Heating takes place very quickly and in a very limited closed area, energy losses for heating the surrounding space are negligible compared to other welding technologies. The energy cost advantage can be tenfold.

Excellent weld quality. With a correctly selected technological mode, the weld zone and heat-affected zone will become almost identical in their structure and features to the main metal. In addition, there are practically no defects in the weld material: porosity, cavities, cracks, impurities.

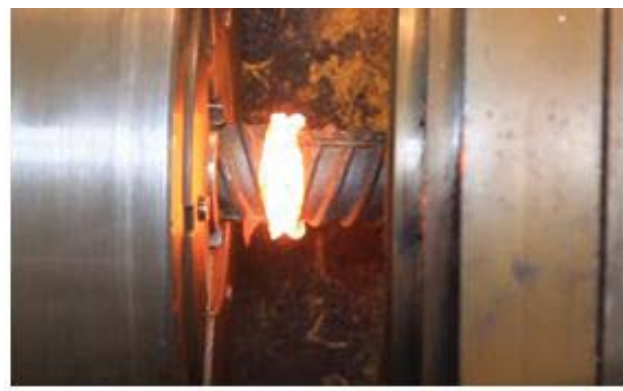

a)

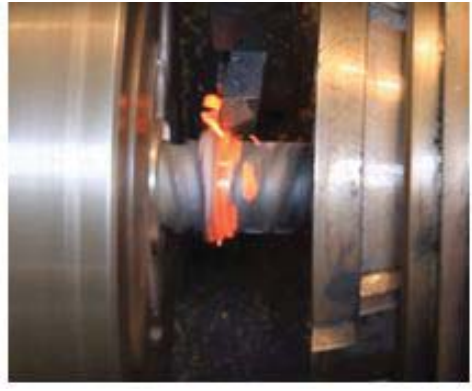

b)

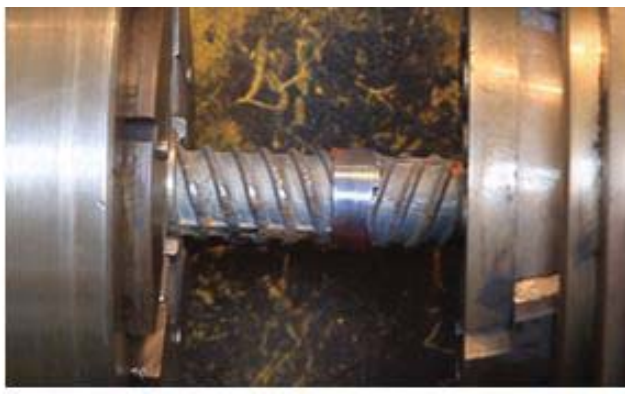

c)

Figure 5: Friction welding process: a) the process of friction welding; b)the process of removing flash; c) after friction welding 
High stability of welds features inside the batch of parts. If the mode precisely is maintained, the details of parts will differ by a fraction of a percent. This enables to control quality selectively and saves a lot of time and money. If one part from the batch has passed destructive test, then a technically proved decision can be made about the suitability of the entire batch.

There is no need for preliminary mechanical cleaning of the surface of the weld zone and the heat-affected zone. It is carried out at the first stage of the technological process. Since it takes more time for preparatory and final operations than for welding itself, this advantage provides an opportunity for very noticeable efficiency.

Ability to weld dissimilar metals and alloys. Such pairs of metals that are simply impossible to weld by other methods are successfully welded: steel alloys with aluminum, aluminum with copper, steel with titanium, etc.

Both environmental pollution and harmful factors affecting human health are minimized: high voltage, splashes of molten metal, ultraviolet radiation, fire hazard, and others.

In addition, friction welding is easily mechanized and automated. This is especially important for large-scale and mass production. Several simple repetitive operations are easily algorithmized and can be performed according to the program without human intervention.

However, there are a number of disadvantages of friction welding, which restricts its widespread introduction in production:

1. Applicability to a limited set of initial shapes. At least one of them must have the shape of a body of revolution. The method is not suitable for welding long straight and curved welds, shells of complex shape, installation of building structures, cases of mechanisms and vehicles. However, in mechanical engineering more than $75 \%$ of parts have a circular cross section or a more complex shape of bodies of revolution.

2. Bulky equipment. Universal or specialized machine requires stationary installation, power supply. This does not let to apply the method in the field.

3. Limited part size. The length of the welded part is limited by the stickoutof a machine's headstock, the diameter - by the stickout of chuck jaws.

4. Radial deformation of the grain in the weld zone and in the heat-affected zones. At strong dynamic loads, fatigue stress concentration and the formation of microcracks and other defects are possible. Corrosion resistance is also reduced. To avoid these phenomena, flash is left on a blank. Additional labor input is spent on removal of flash according to structural requirements. The above disadvantages that limit the use of the method do not allowconsidering friction welding as a universal technology.

Currently, to eliminate the above-mentioned drawbacks of friction welding, research work is being conducted at "Technological Machines and Equipment, Mechanical Engineering and Standardization" department of Karaganda State Technical University (Kazakhstan) $[7,8,9]$. A new method of friction welding is being developed based on the mechanism of thermofriction processing methods $[10,11]$, and a special device is being developed for joining wastes of homogeneous and in homogeneous, off-measurement rebars, rods and wires by friction welding $[12,13,14]$. The developing friction welding technology will have significant advantages in terms of welding quality, versatility, and easy accessibility in comparison with traditional methods.

\section{CONCLUSIONS}

As a result of the conducted researches, the following main disadvantages inherent in existing methods of joining reinforcing bars were established: the narrowness of technological capabilities, low quality and accuracy of the joining, the bulkiness and high cost of technological equipment.

It was established that among the methods of joining reinforcing bars during reinforced concrete products manufacturing, the most effective way is friction welding. However, the following drawbacks restrict its widespread use:

- applicability to a limited set of initial shapes;

- the bulkiness of the used equipment requires a stationary installation, power supply, which does no let to use the method in the field;

- limited size of the joined parts;

- the formation of radial deformation of the grain in the weld zone and in the heat-affected zones. The complexity of the operation spent on removing flash.

To eliminate the above disadvantages, a new method of friction welding for joining reinforcing bars is proposed, which will have significant advantages in welding quality, versatility and easy accessibility.

\section{REFERENCES}

1. [Electronic resource] http://okarkase.ru/strojmaterialy/soedinenie-armatury-svarkoj-vidy-preimushhestva-gost.html\#vidy-soedineniya-armatury

2. [Electronic resource] http://fb.ru/article/343558/sposobyi-svarki-armaturyi

3. Setkov, V.I.,Serbii, E.P. (2005). Building Constructions: Text book. - 2nd ed., sup. and rev. - M.: INFRA-M.- $448 \mathrm{p}$

4. Tsai, T.N. (2012). Building Constructions. Reinforced Concrete Structures: Textbook. 3rd ed. - SPb: Publishing House "Lan". - 464 p.

5. Mulin, N.M. (1990). Rod Reinforcement of Reinforced Concrete Structures. - M.: Stroyizdat.- 233p. 
6. Baikov, V.N.,Sigalov, E.E., (1991). Reinforced Concrete Structures: General course: Text book for universities. -5 th ed., and sup. - M: Stroyizdat. -767 p.

7. Sherov, K.T., Sikhimbayev, M.R., Sherov, A.K., Donenbayev, B.S., Rakishev, A.K., Mazdubay, A.V., Musaev, M.M., Abeuova, A.M. (2017). Matematical modeling of thermofrictional milling process using ANSYS WB software. Journal of Theoretical and Applied Mechanics, Sofia, Vol. 47, No. 2. P.24-33. https://doi.org/10.1515/jtam-2017-0008

8. Sherov, K.T.,Baizhabaginova, G.A., Gurba, G., Imasheva, K.I. (2010). Friction Welding is a Promising Direction of Thermofriction Technology of Working and Joining Parts (overview-1). Scientific works of M. Auezov SKSU. - Shymkent: Publishing House "NurlyBeine". No 2 (20).- P. 96-103.

9. Sherov, K.T., Gurba, G., Imasheva, K.I., Bykova, N.A. (2010). Friction Welding is a Promising Direction of Thermofriction Technology of Working and Joining Parts (overview-2). Science Bulletin of S. Seifullin Kazakh Agro Technical University.- Astana: Kaz AU Publishing House.-№4 (66) - P. 133-138.

10. Boyarski, V.G., Sherov, K.T.,Mussayev, M.M. (2012). Tool for Welding a Hole in a Steel Part. Innovative patent No. 26582 of the Republic of Kazakhstan for an invention. Bul. No.12.

11. Sherov, K.T. (2017), Friction Tool-Rod for Welding Holes in a Steel Part. Patent No. 2183 of the Republic of Kazakhstan for a utility model. Bul. No. 10.
12. Sherov, K.T., Mukysh, B.B., Zhanuzakov, S.Zh. (2016). Development of a New Research Method of Friction Welding. Works of international scientific and practical conference "Integration of Science, Education and Production is the Basis for the Implementation of the Plan of the Nation" (Saginov readings No. 8), Part 3. - Karaganda: KSTU Publishing House. - P.149-151.

13. Sherov, K.T., Baktybai, I.S. (2019). Device for Friction Welding. Abstracts of the Republican student scientific conference "The Contribution of Youth Science to the Implementation of the "Kazakhstan-2050 Strategy", dedicated to the 120th anniversary of K. Satpayev and the Year of Youth in the Republic of Kazakhstan. - Karaganda: KSTU Publishing Pouse. - P.652-653.

14. Esirkepova A.B., Sherov, K.T. (2019). The Use of Measuring Wastes of a Rebar in the Production of Reinforced Concrete Products. Works of international scientific and practical conference "Integration of Science, Education and Production is the Basis for the Implementation of the Plan of the Nation" (Saginov readings No. 11), Part 4. - Karaganda: KSTU Publishing House. - P.363-365. 